\title{
Review on Gender and Poverty, Gender Inequality in Land Tenure, Violence Against Woman and Women Empowerment Analysis: Evidence in Benin with Survey Data
}

\author{
Baoubadi Atozou ${ }^{1,2,3}$, Radjabu Mayuto ${ }^{4,5}$ \& Alexis Abodohoui ${ }^{4,5}$ \\ ${ }^{1}$ Department of Agri-food Economics and Consumer Science, Laval University, Quebec, Canada \\ ${ }^{2}$ Center for Research on the Economics of Environment, Agri-food, Transports and Energy (CREATE), Laval \\ University, Quebec, Canada \\ ${ }^{3}$ Egg Industry Economic Research Chair, Laval University, Quebec, Canada \\ ${ }^{4}$ Department of Management, Laval University, Quebec, Canada \\ ${ }^{5}$ Stephen A. Jarislowsky Chair in International Business, Faculty of Business Administration, Laval University, \\ Quebec, Canada \\ Correspondence: Baoubadi Atozou, Department of Agri-food Economics and Consumer Science, Laval \\ University, Quebec City, Quebec, G1V 0A7, Quebec, Canada. Tel: 1-581-777-4874. E-mail: \\ baoubadi.atozou.1@ulaval.ca
}

Received: September 16, 2017

Accepted: October 18, 2017 Online Published: November 29, 2017

doi:10.5539/jsd.v10n6p137

URL: https://doi.org/10.5539/jsd.v10n6p137

\begin{abstract}
Inequalities in opportunities and rights between women and men have occupied many researchers over the last two decades. This study reviews literature on (i) gender and poverty, (ii) inequalities in land rights between women and men and their implications for the economic and social development of rural areas in developing countries, and (iii) violence against women in the rural population. World Bank survey data (3507 rural households) were used to analyze women's perceptions of agricultural land rights and violence against women in Benin. The Poisson model is adopted to investigate the determinants of physical violence against women in rural households in Benin. The results show that women are more vulnerable to poverty than men. Women are disadvantaged in access to productive assets such as access to credit and arable land, education, labor market, control of incomes earned in households, and are excluded in decision-making in households and institutions. The results also highlight that women in rural areas do not have access to land and do not participate in land management decisions. Based on the Poisson model, the results show that restrictions imposed on women by their spouses significantly increase the number of physical violence against women in households. Moreover, the results suggest also that an increase in the economic value of assets owned by women significantly reduces the incidence of physical violence against women in households. These results suggest that implementing development actions to increase incomes and empowerment women helps to reduce poverty, increases food security, reduces violence against women, and improves household welfare.
\end{abstract}

Keywords: gender inequality, poverty, violence against women, land tenure, women's rights access to land

\section{Introduction}

The relationship between inequalities in access to resources between men and women and poverty is a problem that has preoccupied researchers to improve people's living conditions and social well-being (Kabeer, 1999). It has strongly integrated international development with non-governmental organizations, and especially international institutions such as the World Bank, Food and Agriculture Organization of the United Nations (FAO), United Nations Children's Fund (UNICEF) and United Nations Development Programme (UNDP) in recent decades as a strong focus for poverty reduction in developing countries.

All these organizations working for international development have stressed through the international forums the importance of gender equality and the integration of women in all development programs and projects and at every stage of their implementation in order to promote the social, economic and political empowerment of women (Huyer and Mitter, 1995), both in developed and developing countries. Kimani and Kombo (2010) 
suggest that poverty has a gender dimension. Indeed, in developing countries, the rural and agricultural populations are the poorest and women are most affected by extreme poverty. This is partly due to growing inequalities in developing countries. Many researchers have shown that the unequal distribution of wealth created, difficulties in accessing education, difficulties in accessing resources and health infrastructures are all factors explaining this situation (Svallfors, 1997; Phillips, 2004; Qian, 2017; Kinkingninhoun-Mêdagbé Diagne Simtowe Agboh-Noameshie and Adégboda, 2010). However, in developing countries, the situation of inequality is very high and traditional practices, as well as education and open-mindedness in rural areas, are obstacles to the empowerment of women. Therefore, the reduction of these inequalities between women and men in the rural world has been a major objective of the international development projects implemented in developing countries in recent years. As suggest Kimani and Kombo (2010), Meinzen-Dick, Johnson, Quisumbing, Njuki, Behrman, Rubin, Peterman and Waitanji (2011) to increase poverty reduction, efforts in planning and programming must focus on women and men equality in human resource development, health, employment, physical infrastructures access, agriculture, rural development, trade, public safety, law and order. Some authors such as Kinkingninhoun-Mêdagbé and al. (2010) and Kumase, Bisseleua and Klasen (2010) mentioned that improve the agricultural productivity of women needs for policymakers and development agencies to increase women' access to production resources and inputs technologies. Because women are disadvantage in productivity is due to slight advantage when controlling for all the factors affecting productivity. Generally, men have higher input measures than women (Peterman, Behrman and Quisumbing, 2010; Manfre, Rubin, Allen, Summerfield, Colverson and Akeredolu, 2013; Sraboni, Malapit, Quisumbing and Ahmed, 2014).

Gender-based inequalities constrain women's ability to participate in efforts to enhance agricultural production and reduce poverty and food insecurity (Ransom and Bain, 2011; Seebens, 2011). Reducing these inequalities is a means of improving people's living conditions and consequently reducing poverty (Holmes and Jones, 2011). The link between gender and poverty has thus been widely debated in the world of research on the economic and social development of the South' countries. Another issue that has grown in recent years as a means of alleviating poverty and improving the living conditions of rural populations is unequal access to land between men and women. Income inequality, inequality of opportunity between men and women in the labor market, gender inequality in decision-making, unequal opportunities in access to resources such as land, inequality of freedom of expression between women and men, especially in rural areas, and inequalities in land rights are obstacles to economic and social development and consequently to poverty reduction (Maksimov, Wang and Luo, 2017). Inequality of land rights between men and women is seen as another factor hindering development and poverty reduction.

This article seeks (1) to make a literature review on (i) the link between gender and poverty, and (ii) on the inequalities of land rights between women and men and their implications on the economic and social development of rural areas in developing countries; and (2) to conduct an African empirical gender issues on land rights and violence against women using Benin survey data.

The remainder of the paper is structured as follows: The second section reviews recent research on gender and poverty reduction, gender and land ownership, and economic and social development, and violence against women. The third section analyzes some of the gender indicators in Benin's agricultural sector, women's empowerment and violence against women in rural Benin. The concluding section presents the conclusion and recommendations.

\section{Literature Review}

\subsection{Gender and Poverty}

The integration of women into socio-economic activity has become an inescapable symbol of international development, poverty reduction, increasing the power of women in political decision-making and economic consequences of society, and hence factor of increased food security. The international community is stressing the importance of mainstreaming gender equality in decision-making, programs and projects at all levels to promote social, economic and women's empowerment (Huyer and Mitter 1995). Buvinic and Gupta (1997) point out that women heads of household deserve special attention because they experience the burden of poverty, gender discrimination, and lack of support as heads of households. Women heads of household are common in sub-Saharan Africa.

The relationship between gender and poverty is a complex and controversial issue that is now much more relevant in debates on social and economic development to eradicate poverty (Cagatay, 1998). Cagatay (1998) in his study on the link between poverty and gender emphasized that (i) women compared to men have a high incidence of poverty; (ii) women's poverty is more severe than that of men, and (iii) the incidence of women's 
poverty continues to increase over time compared to men. The vulnerability in terms of poverty and well-being of female-headed households is explained by the fact that women are subject to discrimination in the labor market, access to credit and other markets (Cagatay, 1999; Kehler, 2001; Seebens, 2011; Ragasa, Berhane, Tadesse and Taffesse, 2012). Women heads of households with young girls usually face time constraints and limit their hours of work (Cagatay, 1998). They are often employed only as temporary workers or laborers during the harvest period or during other periods of intensive farm work (Kehler, 2001). Gender inequalities in the distribution of income, access to inputs of production such as credit, ownership control or control over earned income, as well as inequalities in labor markets and social exclusion women undergo in a variety of political and economic institutions are the basis of women's great vulnerability to chronic poverty (Cagatay, 1998). According to Cagatay (1998), gender inequalities are strongly correlated with poverty. Vulnerability in poverty is a function of the productive assets available to individuals (World Bank, 1999).

The more productive assets the great the production, and the lower the household's vulnerabilities in food security and health. Women and children are the most vulnerable because tradition, especially in developing countries, gives them less decision-making power and less control over assets than men, while at the same time their opportunities for self- engage in paid activities and acquire assets are limited (Zuckerman and Garrett 2003). Women face gender barriers in access to financial services, access to property rights and land use, and low levels of education (World Bank, 1999; Suda, 2002). According to Kevane and Wydick (2001), targeting women in credit programs increases the welfare of households and consequently the decline in poverty. Khandker (2005) examined the impacts of microfinance on poverty on participants in the microfinance program in Bangladesh. The results suggest that access to microfinance contributes to poverty reduction, especially for treated women, and poverty reduction at the village level. The author found that an increase in the credit granted to women who participated in the TK 100 microfinance program (1998/1999) leads to an increase in the annual total household expenditure of TK 21, of which TK 11.3 is an increase in expenditure And TK 9.2 for non-food expenditures. On the other hand, the contribution of the increase of TK 100 to the men who participated in the microfinance program on the total expenditure of their households is statistically zero (Khandker, 2005). For Sraboni, Malapit, Quisumbing and Ahmed (2014), increase in women' empowerment are positively associated with calorie availability and dietary diversity at the household level.

For Kabeer (2005), women's poverty and lack of decision-making power tend to go hand in hand, because of the inability to meet basic needs and hence increases the power of others. Thus, this poverty deprives women of their decision-making power, of their rights to claim the resources of the household, of their right to act according to their choices for the good of the household, and even lead them to accept violence in the hands of their husbands (Kabeer, 2005). Sen (1999) in his study in southern Bengal showed that educated women are perfectly capable of managing their husbands' problems of violence. Access to high school can make an important contribution to increasing women's ability to exercise full control over their lives. Kabeer (2005) argued that educated women are also likely to suffer less from forms of domestic violence. But also, it must be emphasized that a strong dependence of the woman and of all the household in verse man also limits the power of the woman to take control of its life. The wealth of the woman, the value of her assets and goods can help minimize domestic violence, increase her decision-making power in the household and in the community, and then have full control over her life choices. In sub-Saharan African countries, the phenomenon is frequent, that is, it is men who generally provide all household needs in rural areas. And in these circumstances, the woman's choices are limited and she has no capacity to express her rights.

Murthy, Sagayam, Rengalakshmi and Nair (2008) suggest that there is no automatic link between the possible objectives of women's livelihood interventions: increasing women's economic efficiency, reducing women's poverty and their dependencies, and support the empowerment of women. Nevertheless, increasing women's control over new production processes and giving them, new market opportunities is essential to increase women's economic power and substantially reduce poverty in the context of privatization Murthy et al. (2008). The author mentions it is necessary for agricultural interventions not only to target individual women engaged in agriculture but also to form women's communities in agriculture. Murthy et al. (2008).

\subsection{Gender and Land Rights}

Most studies on land ownership rights have focused on tenure security and land transfer rights (Markussen, Tarp and Van den Broeck, 2011). The author claim that the rights of land users are limited. Using panel data on farm households in Vietnam, Markussen et al. (2011) showed that restrictions on crop choices limit the diversification of crops. These restrictions limit the labor supply of households. Consequently, it limits agricultural productivity and food security. Keswell and Carter (2014) land transfers have large impacts on the well-being of poor households. In their analysis of the link between poverty and land redistribution, the authors assessed the effects 
of the land redistribution program for the development of agriculture in South Africa. The results show that treated households compared to untreated households (not benefiting from the program) increased their per capita consumption by an average of $25 \%$. Thus, the redistribution of land for agricultural activities contributes significantly to reducing the level of poverty, improving the well-being of vulnerable and poor households (Keswell and Carter, 2014). Land rights and land tenure security lead to an increase in agricultural investment (Markussen and Tarp, 2014), an increase in agricultural productivity, an increase in food security and thus an improvement in the well-being of the poor. Moreover, increasing gender mainstreaming in the agricultural sector helps to amplify this positive effect on rural populations. Aguilar, Carranza, Goldstein, Kilic and Oseni (2014) find in their study in decomposition of gender differentials in Agricultural productivity in Ethiopia that, with $23.4 \%$ gender differential in Agricultural productivity estimated, $10.1 \%$ points are explained by differences in land manager characteristics, land attributes, and unequal access to resources. Ali et al. (2013) assessed the short-term impact of a land regulation program in Rwanda on the environment and access to land by gender. Their results show that (i) the program increased access to land for legally married women, about $76 \%$ of married couples, and good registration of land ownership rights without gender bias (ii) the program has profound impact on agricultural investment and soil conservation measures and these effects are more pronounced in households or women are heads of households, and (iii) the program has severely curtailed the land market. Traditional and cultural patrilineal and matrilineal systems are the weaknesses of land tenure security in African countries (Berge, Kambewa, Munthali and Wiig, 2014), women's access to land and an obstacle to women's rights to inherit their lands parents. According to Chernina et al. (2014), land ownership reforms improve economic conditions in the reformed areas.

In developing countries, and particularly in Sub-Saharan Africa, women are marginalized in the redistribution of agricultural land and other use (Peters 2010; Ansoms and Holvoet, 2008). Cultural practices are related to the fact that women are supposed to leave the parental home by officially getting get married. In addition, men have a duty to ensure all consumption, health and education needs in the household. As a result, the distribution of family land is made only between men in the household, with women traditionally excluded. The reality is that women actively participate in the social, economic and educational life of the household. Women's incomes are mostly spent on household needs while men spend most of their income on personal consumption in Africa. Women are obliged to rent land for their agricultural activities. Studies have shown that women adopt agri-environmental practices and contribute more to the survival of their families and to food security than men (Villamor, Van Noordwiik, Djanibekoy, Chiong-Javier and Catacutan, 2014). Women first try to meet the needs for household consumption while men are focused on securing income.

The qualitative analysis of gender norms in Burkina Faso showed that men still own and control most assets, women have great power of decision and control over gardens and their productions at home, and Attitudes towards women with property have become more favorable (Van den Bold, Dillon, Olney, Ouedraogo, Pedehombga and Quisumbing, 2015). The need for gender equality in the agricultural sector has been identified as a relevant policy issue and incorporated into the programs and policy documents (Istenic, 2015) of governments, international institutions and non-governmental organizations. The rigidity of the statutes and gender roles on farm families is explained by the problem of women's unequal access to agricultural property rights and agricultural education and to the persistent weakness of institutional support to increase Participation and power of women in agricultural households (Istenic, 2015). Kieran, Sproule, Doss, Quisumbing and Kim (2015) report that policy-makers and researchers have largely come to the conclusion that strengthening women's property rights is crucial to poverty reduction and achieving equitable growth. In Ethiopia, according to the 2009 socio-demographic survey data, a female head of household handles an average of 4.39 people and has an average property right of 1.73 hectares against a male head of household who has property rights in Average over 2.20 hectares (Krumar and Quisumbing, 2015). Their results show that there is a strong inequality in the ownership of property rights to land and physical assets depending on the type of head of household. Female heads of households are less active and vulnerable to shocks. Oseni, Corral, Goldstein and Winters (2015) and Lawry, Samji, Hall, Leopold, Hornby and Mtero (2016) suggest that, the difference in agricultural productivity between men and women is explained by the difference in the ownership of production assets. As a result, as women are the victims of asset ownership, female-headed households in rural areas are vulnerable to food security, education and well-being. Menon, Rodgers and Kennedy (2017) found in their study on agrarian and welfare reform in Vietnam that land-use rights held exclusively by women or jointly by couples generate beneficial effects that include rising household spending, Women's self-employment, and low vulnerability of households to poverty. 


\subsection{Violence against Women}

Violence against women is widely debated in the literature by researchers and international institutions such as World Health Organization (WHO) and UNICEF and World Bank. Violence against women is recognized against a public health problem by the World Health Organization. The different forms of violence against women by their husbands or spouses according to Watts and Zimmerman (2002) are: (1) differentiate access to food; (2) violence during pregnancy; the psychological abuse of the intimate partner; (3) physical violence by the current partner or trainer; (5) sexual violence by the current partner or trainer. Garcia-Moreno, Jansen, Ellsberg, Heise and Watts (2006) identify important variables that determine physical violence, sexual violence and behavioral control by the intimate partner (husband or partner). For behavioral control, Garcia-Moreno et al. (2006) illustrate seven constraints that are often imposed on women by their husbands or common-law partners:

$\checkmark$ Trying to prevent the woman from seeing her friends

$\checkmark$ Restricting encounters with family of birth

$\checkmark$ Insisting on wanting to know at any time the woman is, strictly control the movements of the woman

$\checkmark$ Ignoring the woman or treating her indifferently

$\checkmark$ Getting angry if she talks to other men

$\checkmark$ Often suspecting the woman of being unfaithful

$\checkmark$ Hoping for a request for permission from the woman before she has health care.

These characteristics are found in developing countries and in recent years' studies on social protection have focused on these characteristics to better understand the situation of the different types of violence and to carry out actions to eradicate them. The level of poverty in developing countries and the high dependence of women on their husbands on livelihoods such as consumption and health are also factors that exacerbate such violence against women. Women who have no means of subsistence are at the mercy of their husbands and must scrupulously respect the demands of their husbands, failing which they will face the differentiation of access to food, physical and psychological violence; and they will be deprived of any means of subsistence. Consequently, public policies, development projects focusing on improving the living conditions of women, empowering women; And increasing their incomes and reducing women's dependence on livelihoods can significantly reduce violence against women in households in developing countries.

Table 1. Diverse types of violence against women

\begin{tabular}{|c|c|}
\hline $\begin{array}{l}\text { Types of violence } \\
\text { against women }\end{array}$ & Characteris \\
\hline Physical violence & Slaps, shots, kicks and strikes \\
\hline Sexual Violence & $\begin{array}{l}\text { Forced sexual relations, other sexual forms coercion, sexual harassment, dowry violence, } \\
\text { marital rape, female genital mutilation, sexual abuse, forced prostitution }\end{array}$ \\
\hline $\begin{array}{l}\text { Psychological } \\
\text { abuse }\end{array}$ & $\begin{array}{l}\text { Insults, depreciation, constant humiliation, intimidation, destruction of things, threats of } \\
\text { harm, threats to take away children, threats to food, intimidation of women at work }\end{array}$ \\
\hline Behavior control & $\begin{array}{l}\text { Women isolation from family and friends, monitoring of women's movements, restriction } \\
\text { of access to financial resources, employment, education or medical care, prohibition of } \\
\text { visiting the family, restriction of visit to friends, prevented the woman from talking to the } \\
\text { other men, to wait for the woman to ask for permission before seeking health care for } \\
\text { herself, ignored the woman, treated her indifferently, wants to know where she is always. }\end{array}$ \\
\hline $\begin{array}{l}\text { Domestic } \\
\text { Violence }\end{array}$ & $\begin{array}{l}\text { A severe and growing form of domestic violence characterized by multiple forms of abuse, } \\
\text { terrorism and threats and increasingly possessive and controlling behavior on the part of the } \\
\text { aggressor }\end{array}$ \\
\hline
\end{tabular}

For more information see World Health Organization (2012), Ellsberg, Mary Carrol, Heise and Lori (2005): The Guide of Violence Against Women: A Practical Guide for Researchers and Activists, Watts and Zimmerman (2002). 


\section{Data Presentation and Analysis' Method Approach}

We use the part of the World Bank survey database on rural land plans in Benin. The basic survey base covered 3507 rural households in Benin. The survey covered 291 villages in nine regions, of which 192 randomly selected to constitute the treatment group receiving a rural land plan and 99 villages randomly selected to constitute the control group (Goldstein, 2011). This survey covered the gender aspect of land rights, violence against women in households. We used this women module of the database in our analysis. The data in this section covered women's access to agricultural land, questions pertaining to the perception of land acquisition, the perception of rural land security, and questions about male behavior in verse their wives in households. The sample size of the women surveyed in this section is 3247. Data were collected in March and April 2010.

We mainly use descriptive and qualitative methods in our empirical analysis. In addition, a Poisson model is estimated using the maximum likelihood method to investigate the effects of women's behavioral variables by their intimate partners and the economic values of women and partners' assets on the number of violence or dispute over the last twelve months. The following section presents the results and their discussions.

\section{Empirical Results}

\subsection{Women and Land Rights in Benin}

The situation of women's rights on land in Africa is generally determined by cultural and ancestral practices. In the household, responsibilities are predefined by culture: man, works to feed the family and the woman takes care of the children and housework. The possession of land in rural areas for agricultural activities according to culture is then the responsibility of men. Women participate actively in agricultural activities, but their access to land rights remains neglected. Figures 1, 2 and 3 present the results of women's perceptions of their inheritance rights to their parents' land in the event of a divorce and in the event of the death of their spouse in Benin.

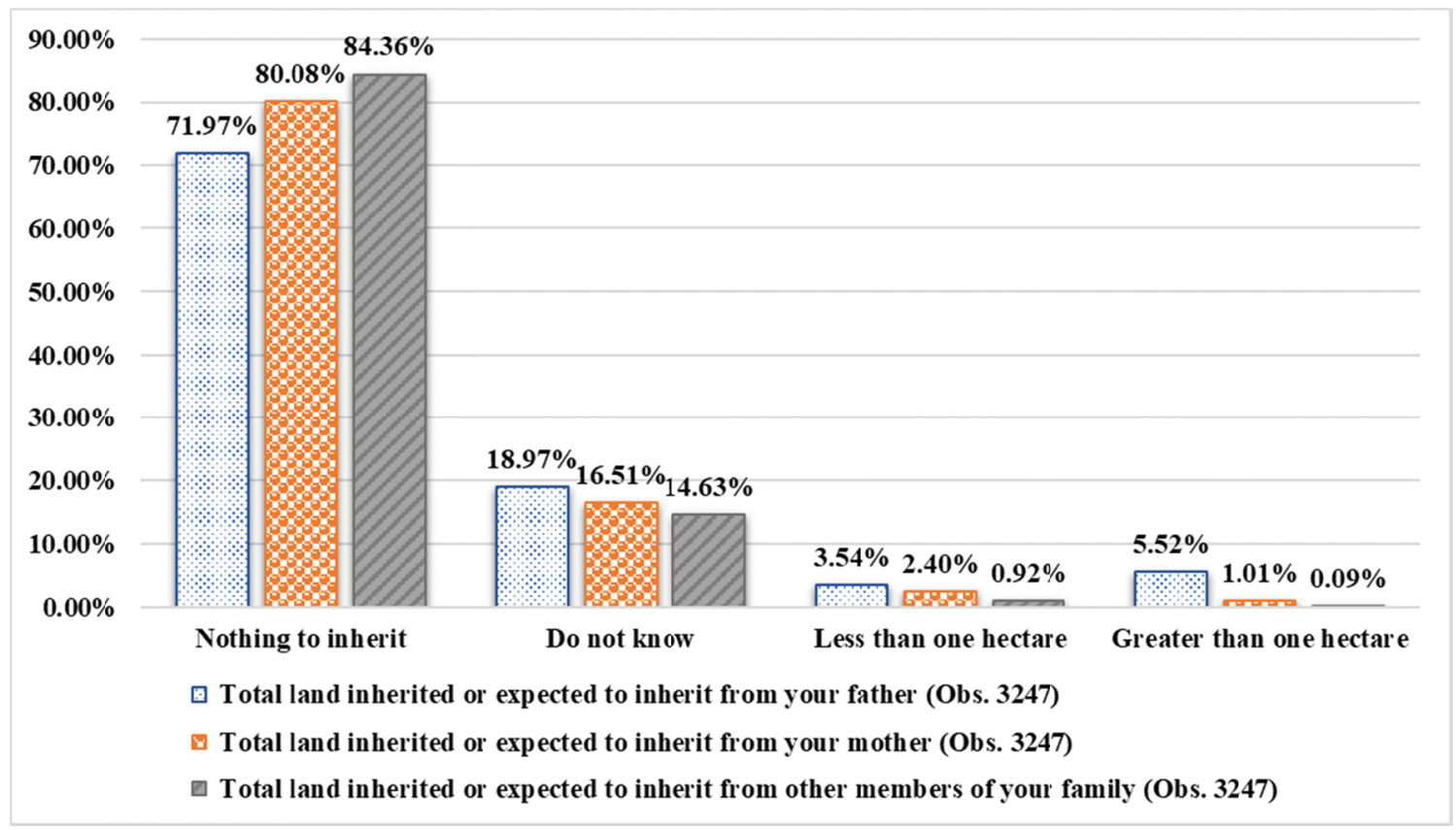

Figure 1. Women perception on their land inheritance rights form their parents and others family 'members

The results of Figure 1 show that of the 3247 women surveyed, almost $72 \%$ of women did not inherit or expect anything inherited from their fathers, more than $80 \%$ have inherited nothing and hope for nothing inherited of their mothers. Similarly, almost $85 \%$ of women have not inherited anything and do not expect anything from another member of their family. However, a small proportion of women inherited or hopefully inherited the land from their parents and one of their family members. Indeed, $3.54 \%, 2.40 \%$ and $0.92 \%$ of women hope to inherit less than one hectare of their fathers, mothers and a member of their families. In addition, $5.52 \%$ of women expect to inherit more than one hectare from their fathers, $1.01 \%$ expect the same from their mothers. More than $14 \%$ of women do not know if they will inherit the land from one of their families. These results show that women do not have access to land in Benin. Figure 2 highlights the rights of women on their households' land in the event of divorce. 

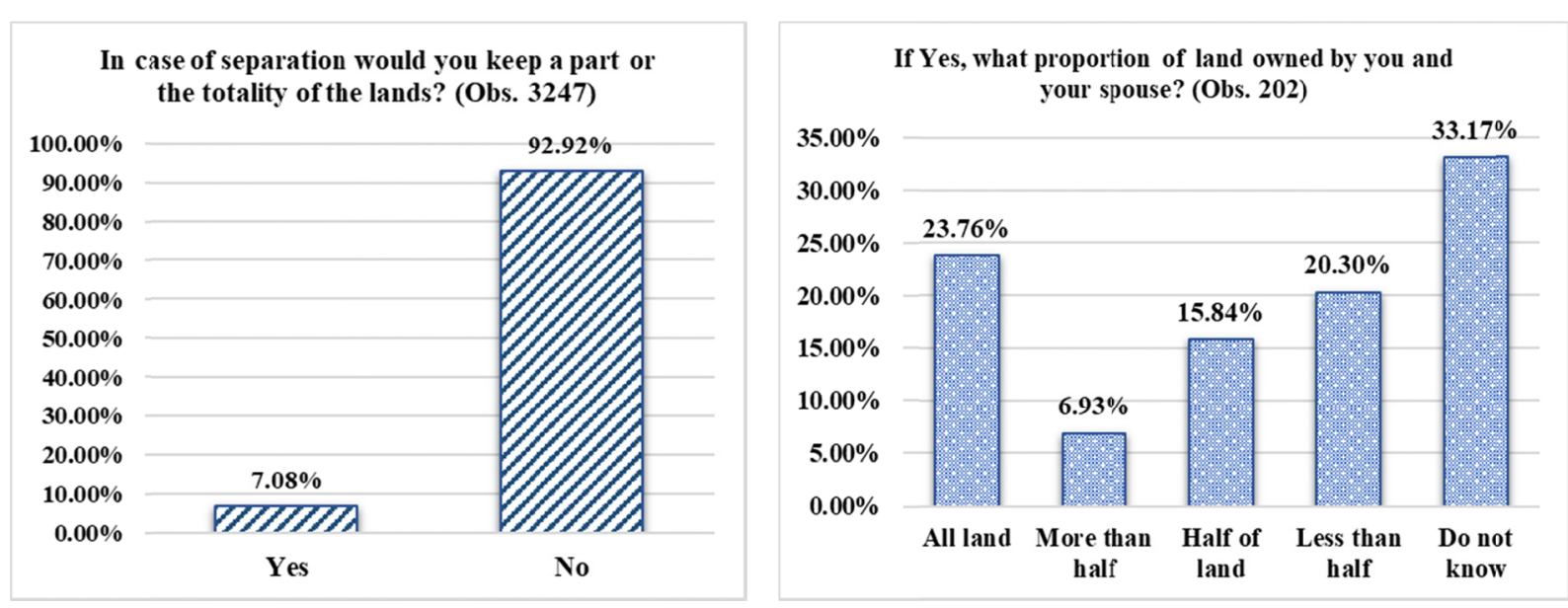

Figure 2. Women perception on their land-rights from their household in case of divorce

The results show that $92.92 \%$ of women say they have no rights over part and all their households' land in the event of a divorce. It is only, $7.08 \%$ who hope to keep some or all of the land in case of divorce. Of these, $23.76 \%$ of women hope to have ownership over all land, $6.93 \%$ on more than half of the land, $15.84 \%$ on half of the land, $20.30 \%$ on less than half of the land in the household. On the other hand, $33.17 \%$ of the women do not know what part of the land would return to them.

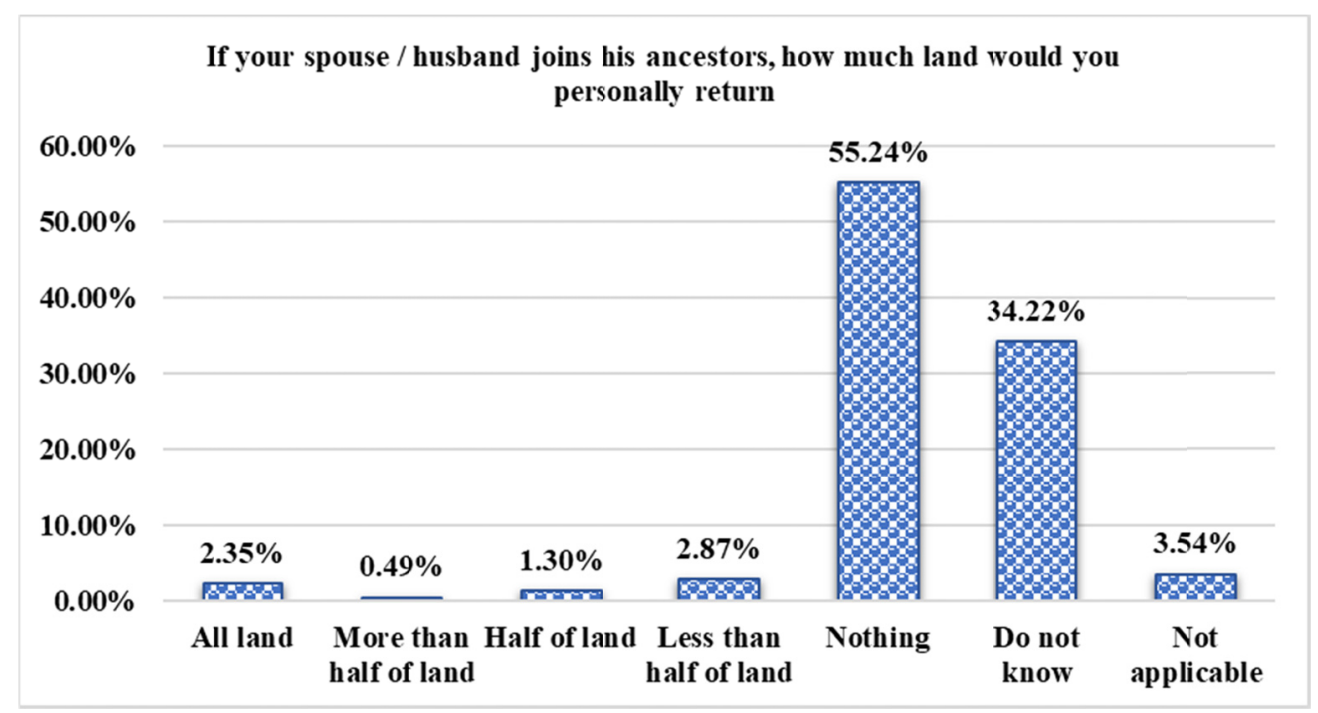

Figure 3. Women right on their household land if their husband dies

Figure 3 shows women's perceptions of their ownership of their households' land in the event of the death of their husbands. The results show that out of 3247 women surveyed, $55.24 \%$ are not entitled to any share of the household's land, $34.22 \%$ do not know if they will obtain the right of ownership over part of the household's land. Moreover, $2.35 \%$ of women are certain to own the right of ownership on all the land of the household, $0.49 \%$ on more than half of the land, and $4.17 \%$ on more than half of the land. This shows that at least 56 women out of 100 will not have access to household land in the event of the death of their husbands. In rural areas, land and the main asset of agricultural activity of the household, the main means and source of life of households. In the event of the death of the husband, it is the woman who takes care of the children in terms of consumption, health and education. As a result, deprived of household land, the family falls into extreme poverty with no source of income. The government must adopt land rights regulatory policies through the land title policy to recognize the private ownership of each farmer. This regulation solves land management problems related mainly to the inheritance of land by integrating women, the right of women's land in case of divorce and the rights of women on all the land in the event of the death of their husbands. These regulations will increase social well-being by reducing poverty. 


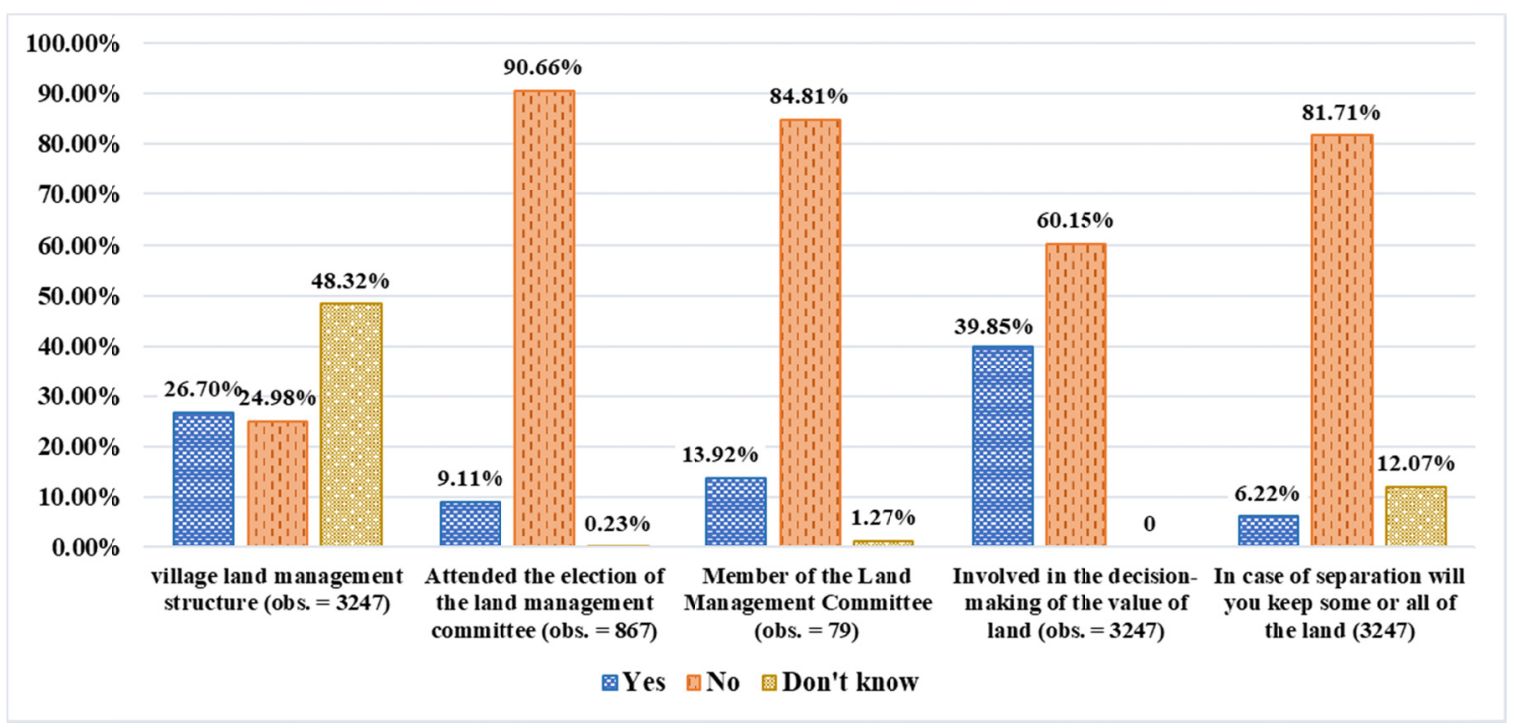

Figure 4. Women implication in the decision on land management and land value in the community

Figure 4 presents the situation of women's participation in land value management and decision-making in rural Benin. $26.70 \%$ of women reported that there is a land management structure in their villages. On the other hand, $48.32 \%$ do not know if there is such a structure in their community, and $24.98 \%$ mention that there is no such structure in their villages. These results are justified by the fact that women are less concerned with land matters given that the majority of women in these rural communities do not have land.

Among the women who found that there is a land management structure in their village communities, only $9.11 \%$ participate in the election of the committee of this land management structure, $84.81 \%$ do not participate in this election. This is always due to the fact that women who have land rights in these communities are negligible, which does not encourage them to participate in land management and value decisions. Of the women who participate in the committee election, $13.92 \%$ are members of the land management committee. The majority of women are less involved in the management of agricultural land because they do not own land, and considers management to be that of men.

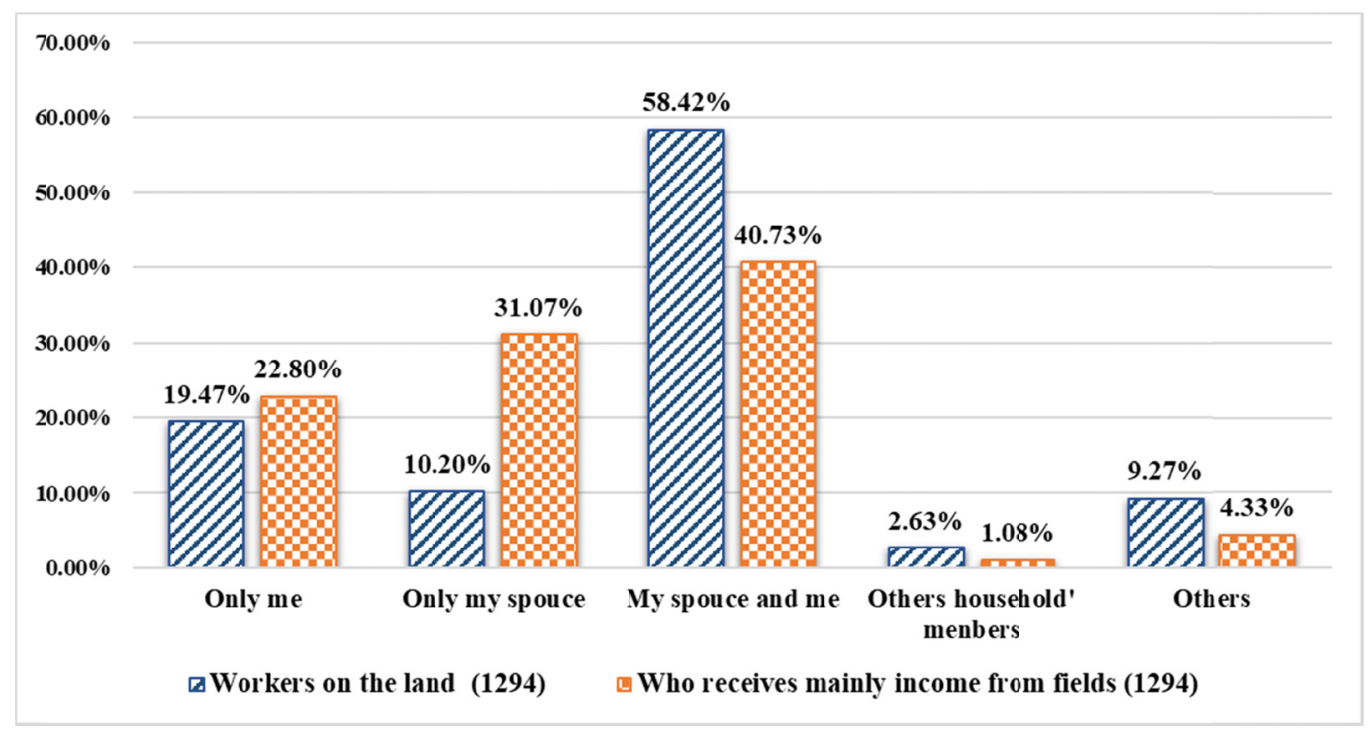

Figure 5. Women participation in supply of agricultural labor on the land, and the distribution of income generated

Although women do not have access to agricultural land, they offer agricultural labor. Figure 5 shows the supply of agricultural labor in households and the distribution of income management generated by these agricultural 
activities. The results show that $58.42 \%$ of women work with their husbands on agricultural land, $19.47 \%$ of women work alone on agricultural land, and $10.20 \%$ of women say that they are the only men who work on their land. However, agricultural incomes are managed in $41 \%$ of cases by women and husbands, $31 \%$ by husbands alone and $22.80 \%$ by women alone. This analysis shows that women offer agricultural labor, but it is the men who manage the income alone in three out of ten households.

Regarding asset ownership (money, physical assets), 30.98\% of women report having no assets (Figure 6). Figure 6 suggest that, during the past 12 months, $25 \%$ of women have applied for loans in cash or in kind, 23\% have obtained and $2 \%$ have not.
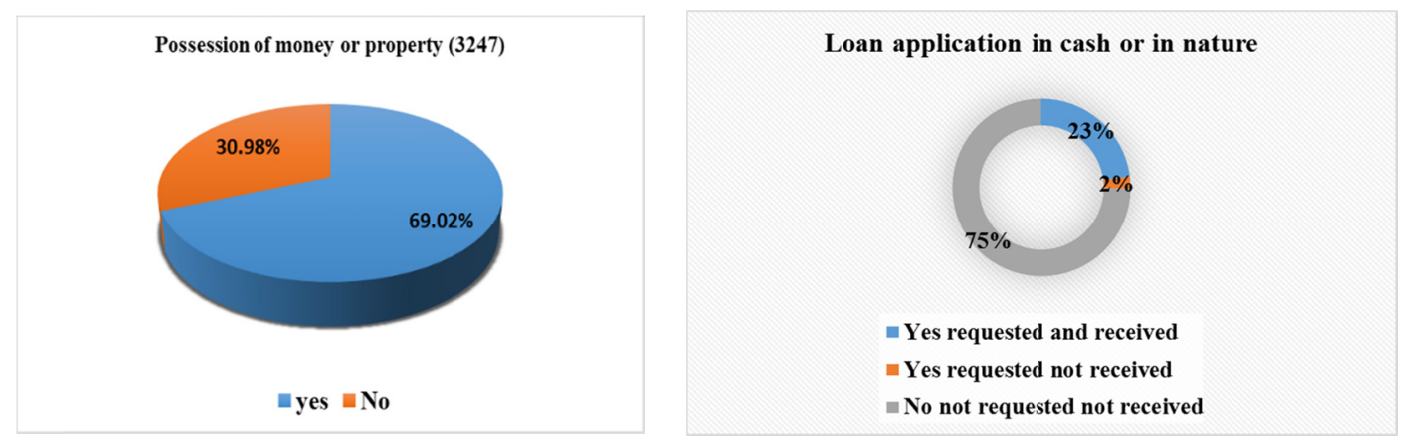

Figure 6. Women property and asset demand situation

\subsection{Violence against Women in Benin' Rural Households}

Violence against women is psychological, moral and physical. In developing countries, such as Benin, these types of violence against women are frequent, especially in rural areas where households suffer from food insecurity and extreme poverty. This section describes the diverse types of violence reported by women in agricultural households in Benin. Figure 7 presents the results related to psychological, moral and physical violence against women. The results show that out of 3247 women surveyed, at least one woman in ten is forbidden by her husband to visit her friends. $6.62 \%$ of women report that their husbands limit their visits to their families. $26.82 \%$ of women emphasize that their husbands want to know where they are always. In addition, $8.75 \%$ of women are ignored by their husbands, and $17.12 \%$ of women are forbidden to talk to other men. Of the 3247 women, 157 women, or $4.84 \%$, reported physical violence against their husbands. Figure 8 shows that among the latter, $15.92 \%$ regularly suffer physical violence from their husbands, $23.57 \%$ often report physical violence against their husbands, and 45 out of 100 women rarely report physical abuse of their husbands. Women in rural areas are in deep poverty and have no wealth or good to value and no income-generating activities. They are thus subject to the decision of their husbands and in fact have no power of decision in the household. The identification and understanding of the determinants of violence against women in couples in developing countries is important in order to make policy recommendations to avoid such violence and to increase the decision-making power of women in households. 


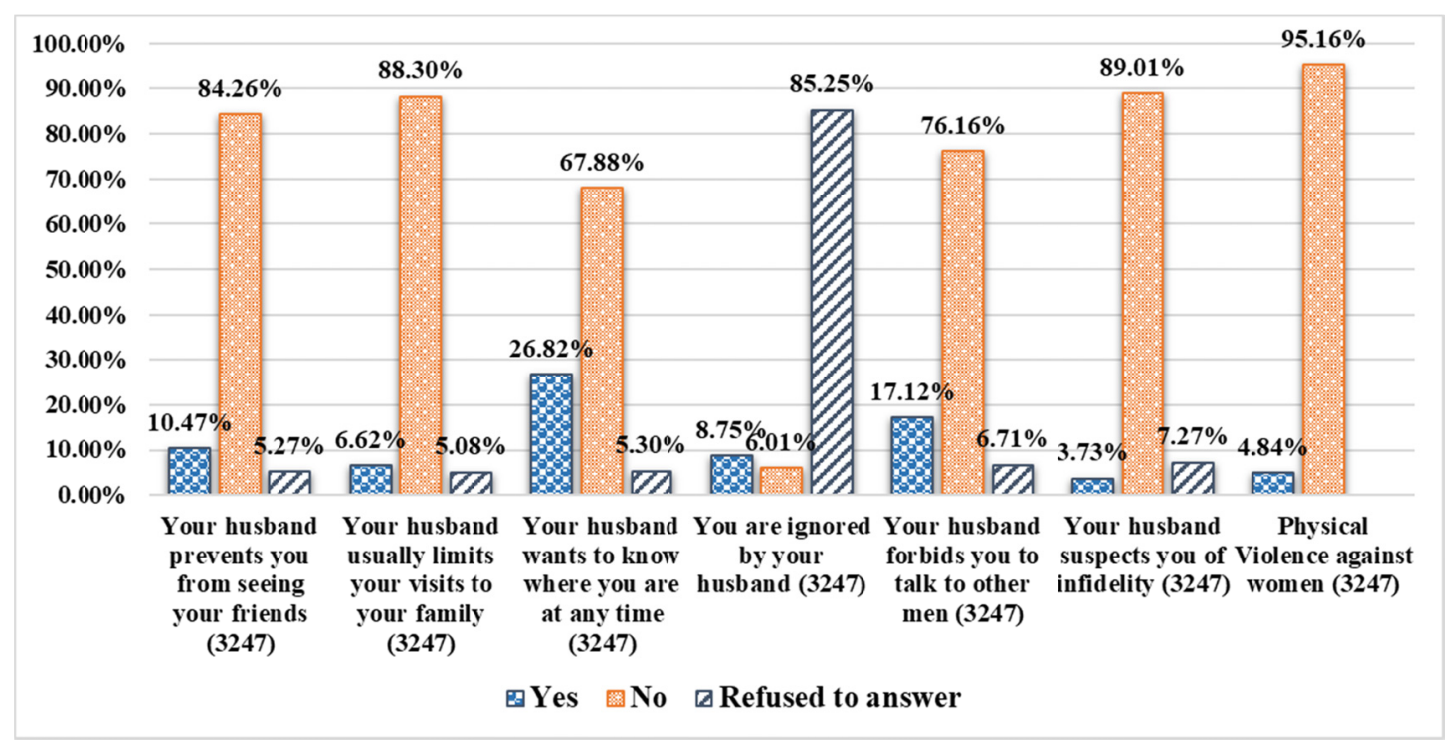

Figure 7. Controlling behaviours (psychological and moral violence) and physical violence against women

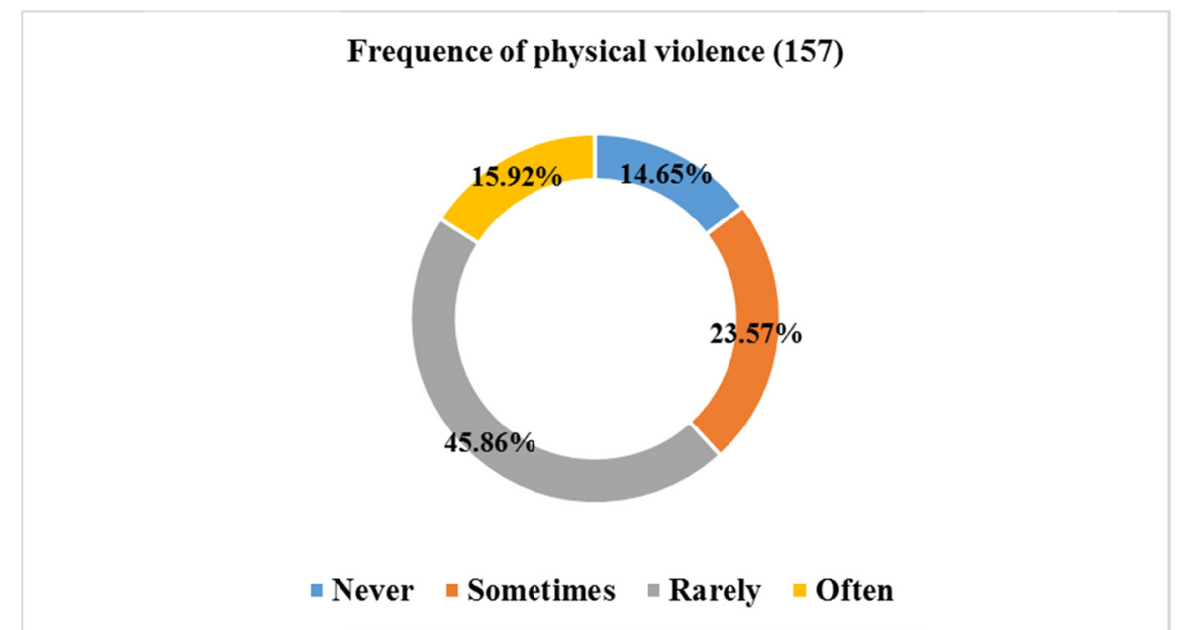

Figure 8. Frequency of physical violence against women in rural household in Benin

\subsection{Empirically Results of Physical Violence against Women' Causes Factors}

We analyzed the effects of restrictions or constraints imposed on women by men on the number of disputes leading to physical violence in agricultural households in Benin. Table 1 presents the results of the Poisson model explaining the number of marital disputes according to the constraints imposed by the husband and the assets values of women and husbands in local currency (FCFA). The results show that the constraints imposed by husbands have positive and statistically significant effects at the $5 \%$ threshold on the number of marital disputes or domestic violence. Restrictions on speaking to other men, ignoring his wife, and limiting women's visits to his family are the major determinants of violence against women in rural Benin. Moreover, the results show that the economic value of women's assets has a negative and significant effect on the number of marital disputes. Putting development policies in place to increase women's wealth and wealth significantly contributes to the elimination of violence against women, their empowerment in decision-making in households and in the community. The results show that the value of men's property has a positive and significant effect at the $1 \%$ threshold on the number of domestic disputes. The more the husband is rich, the more the woman has no power of decision if she is totally dependent on her husband. Women in such situations in rural areas especially in West Africa have the right to discuss the orders of her husband, discuss the behavior of her husband. Women are oppressed in this situation for much of cases. In order to reduce violence against women in sub-Saharan Africa and particularly in Benin, development projects need to focus on gender by seeking to reduce income inequality 
between men and women, generating income for women, increasing women's incomes and increasing women's self-confidence.

Table 2. Determinant factors of violence against woman in the rural household of Benin, results of Poisson regression

\begin{tabular}{lc}
\hline \multicolumn{2}{c}{ Number of dispute with your husband on the last twelve months } \\
\hline Independent variables & Poisson Model \\
\hline Your husband prohibited you to talk to other men $(1=$ Yes $/ 0=\mathrm{No})$ & $0.708^{* * *}$ \\
& $(-0.070)$ \\
Your husband ignored you $(1=$ Yes $/ 0=\mathrm{No})$ & $0.262^{* *}$ \\
& $(-0.092)$ \\
In general, your husband limits your visits to your family $(1=$ Yes $/ 0=\mathrm{No})$ & $0.631^{* * *}$ \\
& $(-0.090)$ \\
Possession of money or materiel property $(1=$ Yes $/ 0=\mathrm{No})$ & $0.347^{* * *}$ \\
& $(-0.083)$ \\
Number of children you have in your previously wedding & $-0.120^{* * *}$ \\
& $(-0.020)$ \\
Total value of your property (FCFA) & $-0.703 \mathrm{e}-6^{* *}$ \\
Total value of your husband property (FCFA) & $(-0.238 \mathrm{e}-6)$ \\
& $0.959 \mathrm{e}-6^{* * *}$ \\
Constant & $(-0.112 \mathrm{e}-6)$ \\
& $0.918^{* * *}$ \\
\hline Observations & $(-0.094)$ \\
\hline Pseudo $R^{2}$ & 195 \\
\hline
\end{tabular}

Note: $* * *$ significant at $1 \%, * *$ significant at $5 \%, *$ significant at $10 \%$, and in (.) the standard error

The next section explores the situation of women's rights in local elections, their perceptions of non-participation in general assemblies in their localities.

\subsection{Women Participation in Their Communities' Organizations}

Figure 9 shows that $76.29 \%$ of women still participate in local elections, and $3.54 \%$ say they have never voted. Moreover, $1.92 \%$ of women declare that they do not have the right to vote. Figure 11 shows that $11.77 \%$ of women are members of a local or governmental association. Of the women who have never attended meetings of their communities (586, see Figure 10), 23.01\% declare that they are not useful in organizing their communities, $37.88 \%$ declare that they are not welcome in these assemblies, and more of $15 \%$ pointed out that they were not aware of the organization of community assemblies. These findings suggest that women in the agricultural areas of Benin underestimate their values, and what their interventions can significantly contribute to improving their community, improving decision-making and their ability to defend their rights. 


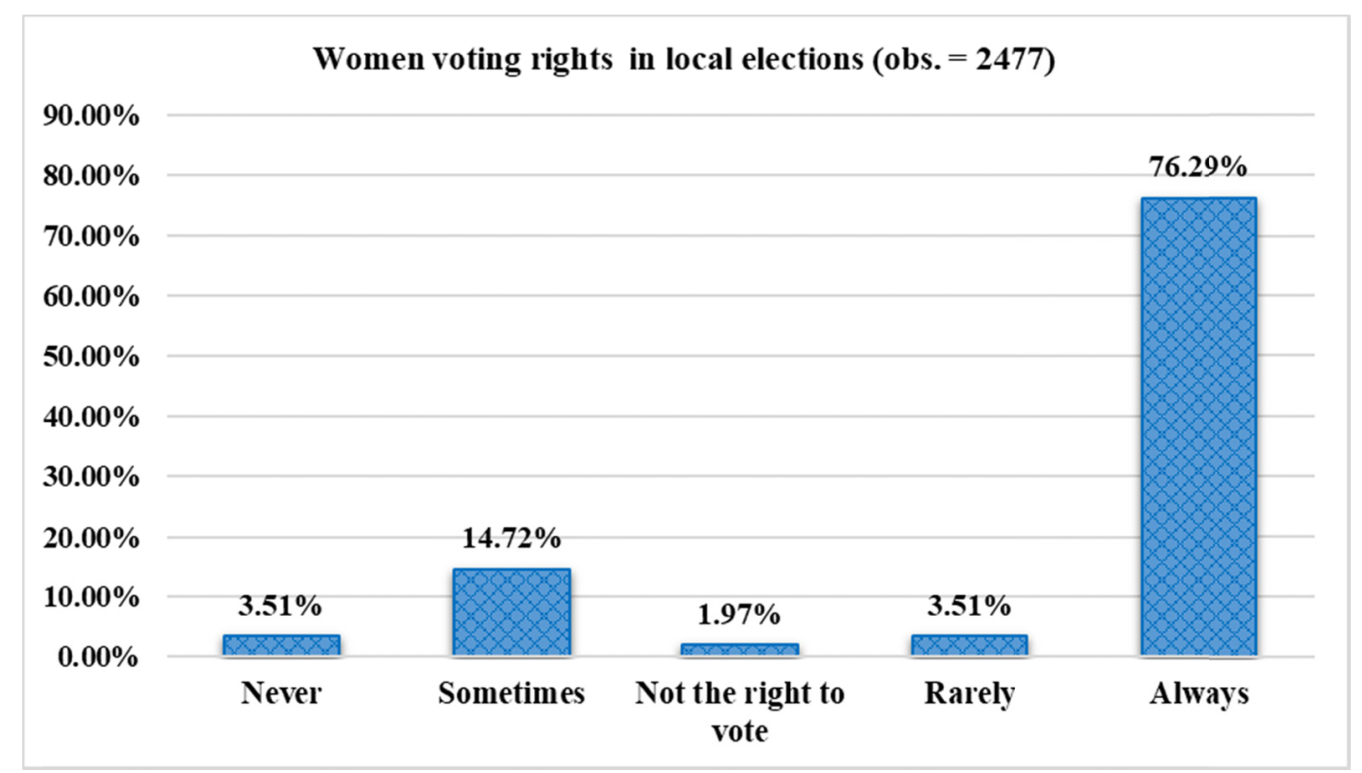

Figure 9. Women voting right in local election

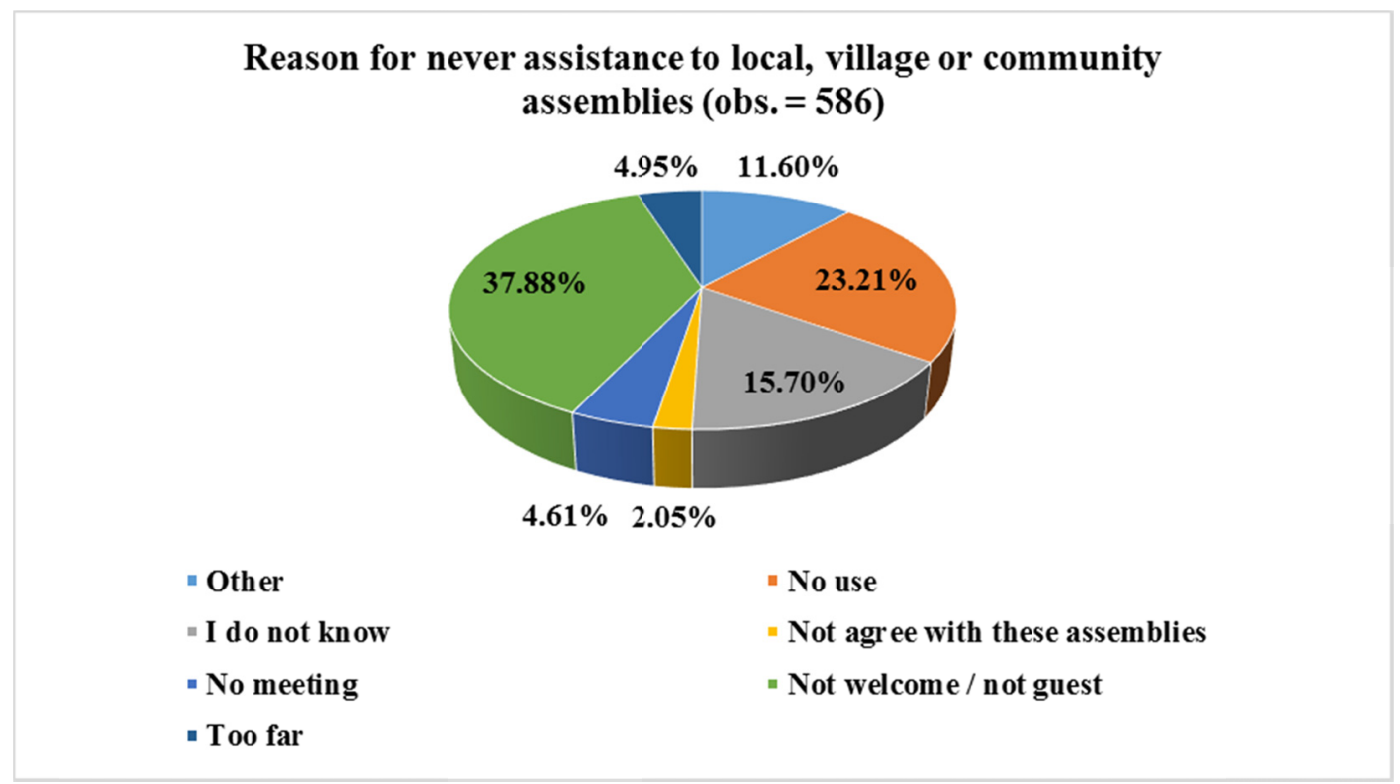

Figure 10. Women reason to never assist to their communities' assemblies

Figure 11 presents the situation of women's active participation in community assemblies. The results show that most women participating in local and community assemblies do not speak (55.45\%) during these assemblies. Women do not participate actively in decision-making in local associations and organizations. It is therefore necessary to organize sensitization campaigns to motivate women in rural areas to actively participate in decision-making in their communities, to improve their self-perception and to integrate them into the organization of the community. It is through this integration and women's self-confidence that they can act and defend their interests and increase their power in decision-making in community-based organizations. 


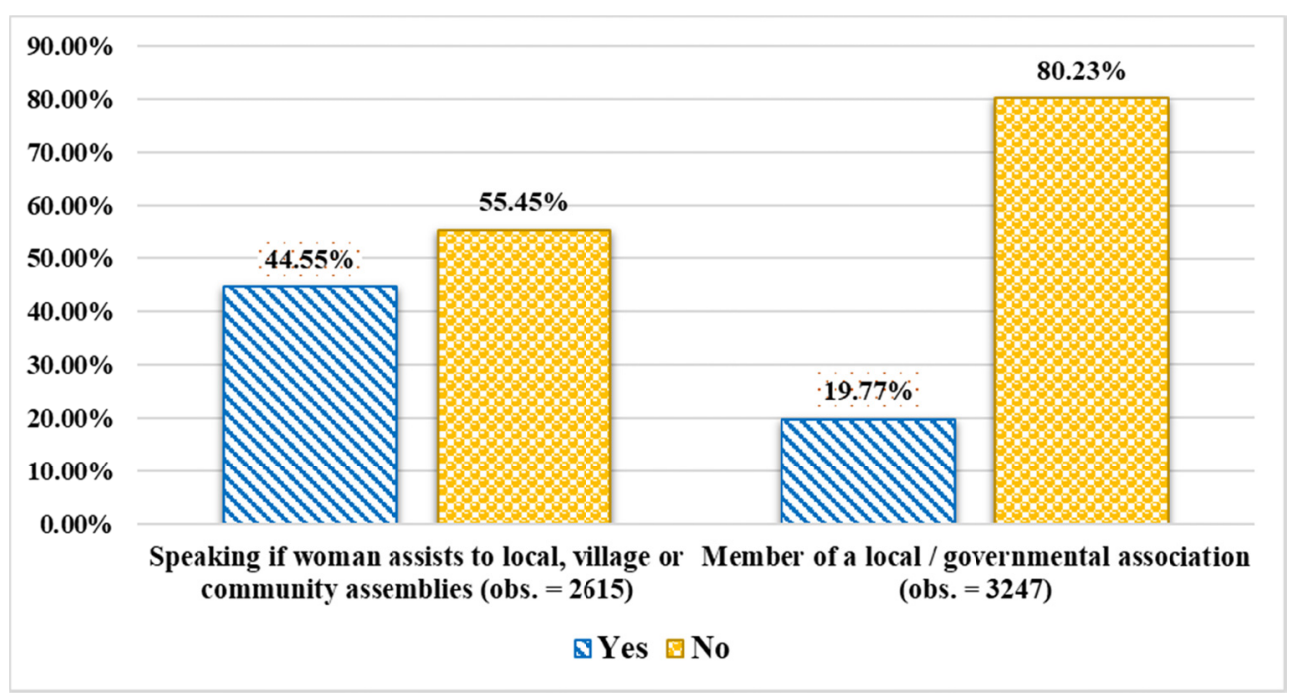

Figure 11. Women actively implication in their communities' assemblies and association

\section{Discussion and Conclusion}

The main objective of this paper is to conduct a literature review on (i) the analysis of the relationship between poverty and gender, and the causes of these gender inequalities in poverty, (ii) access to land of women, and (iii) violence against women. An empirical application has been made of women's property rights and access to land in Benin as well as violence against women in rural households. The database of World Bank survey data on rural land plans in Benin. The basic survey base covered 3507 rural households in Benin. This survey covered the gender aspect of land rights, violence against women in households in rural areas. This section of the database (3247 observations) on women's perceptions of land rights and violence against women was used in the empirical analysis. Descriptive methods were used in the analysis of women's perceptions. The Poisson model is used to analyze the determinants of physical violence against women in households.

The results show that women are more vulnerable to poverty. This situation is explained by the fact that women are discriminated against in the labor market, access to financial services such as credit, access to both production resources, new production and development technologies. In addition, they are marginalized in the decision-making and management of government institutions in households, local governments, and rural cooperatives. These discriminations are exacerbated by social, cultural and traditional practices in developing countries including Africans.

Human development, as measured by the Human Development Index, involves not only economic growth but also raising educational attainment and improving health. Agriculture is not just contributor to human development in its own rights but may also contribute to growth in per capita incomes. Agriculture is a form of education, a form of culture, and a form of saving, causing accumulation of both human, social and economic capital and growth aggregate output if those forms of capital are inputs in the aggregate of production. Therefore, agriculture is the principal economic preoccupation for most of Africa's people. Therefore, agriculture should be the principal economic preoccupation of Africa's policy makers. Taking these shortcomings into account in development projects can improve women's empowerment, reduce poverty and increase food and nutrition security and hence social well-being.

If agriculture is indeed important for development, how should countries go about it? A focus on income distribution, particularly a better distribution of land ownership in agriculture, both to facilitate output growth and accelerate poverty reduction is desirable. Land ownership and land tenure security lead to increased agricultural investment, increased agricultural production, food security, and increased household welfare. Human resources are described as human capital, one more Africa's main asset, and sometimes regarded as economic capital. However, women in developing countries are marginalized in access to agricultural land. This constraint does not lead to improvements in household living conditions, but on the contrary, hinders food and nutrition security. It reinforces "gender gap" The adoption of land laws facilitating women's access to arable land would contribute significantly to household food and nutrition security, increase incomes, reduce poverty and increase social welfare. This means that in all cases, timely cooperation between law enforcement agencies 
(formal and informal institutions) in multiple countries may be necessary for tracing, identification, and empowerment of women beyond a mere law promulgation. In this sense, poverty reduction and then development may occur depending on the speed in effectively closing gender gaps in Africa (World Bank, 2001).

Violence against women is various. It is possible to identify physical violence, sexual violence, psychological violence, moral violence, and the control of women's behavior by their husbands or partners. Controlling the behavior of women in households and women's high dependence on their partners to meet basic needs and household livelihood are the main factors that exacerbate violence against women in developing countries. Development projects aimed at increasing the empowerment of women in households can significantly reduce violence against women.

The results of the analysis of women's perceptions of agricultural land rights in Benin show that women in rural Benin neither have access to land and nor participate in land management decisions. The results of the Poisson model show that restrictions imposed on women by their spouses significantly increase the number of physical violence against women in households. Moreover, an increase in the economic value of assets owned by women significantly reduces the number of violence against women in households. There is some trends raised in literature on violence against women. Many authors theoretically suggest that women empowerment enable to reduce significantly this major public health issue called violence against women (Krug, Mercy, Dahlberg and Zwi 2002; Watts and Zimmerman 2002). At the family level and relationship, on the one hand, the fact in some rural area the male controls wealth and decision making within the family is strongly correlated with frequent marital conflict (Ellsberg and Heise, 2005). On the one hand, however, according to World Health Organization report (WHO 2012), lack of alternative means of economic support, women extreme poverty, low socio-economic status of women explains why women don't leave violent partners. To alleviate this tragic suffering, Kim, Watts, Hargreaves, Ndhiovu, Phetla, Morison, Busza, Porter and Pronyk (2007) indicate that economic and social empowerment of women can contribute to reductions in intimate partner violence. Following in the same vein, Aizer (2010) suggests that decreases in the wage gap (gender wage inequality) reduce violence against women. A household bargaining economic theory that incorporates violence predicts that increase in women' relative wage increases her bargaining power and lower levels of violence by improving her outside option. Our empirically results corroborate this theoretical prediction. Increase rural women' wealth (asset and income value) decreases significantly the violence against women prevalence in the households. Introduction of development projects with plans and programs aiming to increase the incomes and wealth of women contribute to a significant reduction in violence against women in rural households. Such increase allows women to contribute to the household's necessities which were at other times solely under the men responsibility. This also helps increase the subsequent bargaining power of women in household decision-making, her autonomous with regard to the economic means (food provision and consumption, health, education). This significantly reduces men's pressures on women and the dependence of women towards their partners, and hence a significant reduction in violence against women in households.

This means that, with regard to such contributions, social and cultural policies aimed to promote gender and development must not disregard the economic impact which women may have, and especially concerning the African internal market.

\section{Limitations}

Our study involved a number of inevitable limitations, mainly arising from the use of household-based population-level data. For example, we did not have information on individuals neither who had migrated into the surveyed villages from outsider, nor who have become intimidated by/accustomed to violence. The first is of special concern for our research topic given - the sub-cultural difference influence - that coming from another area (internal displacement and migration) is likely to decrease the violence of men in the households. The second, because the local traditions and culture affect people's livelihood options to report or not testimonies about their own life experience. With their refreshingly straightforward accounts of what they have individually lived, most take the safe option of staying silent or lying in order to avoid retaliation. We did not search for intracultural or intercultural incidence due to our research questions.

Another limitation is the assumption of the same age and sex population distribution across all provinces, which will not hold if mortality in surveyed villages has led to skewed sex distributions. Moreover, we could not control factors associated with greater risks victimization: the risk of victimization decreases with age after peaking in the 26-24 age group, the elderly (ages 65 and older) have much lower victimization rates than younger individuals (Vandercar-Burdin, 2011). Accordingly, we also did not consolidate the data according to whether the women are elderly and mothers, and have suffered differently from the reported violence of the 
partner or by considering the nature of the conjugal relationship (wife versus common-law partner or co-wife status).

\section{Policy implications}

The implications of gender inequality in land tenure and violence against woman accumulate their magnitude in maintaining gender and poverty as one of the top concerns in African countries. In the effort to enhance the health and well-being of residents of Benin villages, the government should address woman empowerment. "If people are to collectively address the issues of poverty and injustice, they should start with women and their empowerment" (UN, 2006). More than ten years after Statement submitted by VIVAT International, a non-governmental organization in consultative status with the Economic and Social Council, we believe it is still true today; women continue to bear a disproportionate burden of poverty, illiteracy, ill health, malnutrition and violence. The struggle for women's rights - the struggle against violence against women - is a priority with respect to the justice agenda. Since violence is a form of power, it is really a negative one. It as a cross-cutting issue covering not only education and culture, but also other policy domains such as enterprise, media, research, social and regional policy, and rural development.

If the fight against poverty is the mandate of the State, it must ensure for development by the downstream redistribution (Beaudet and Haslam, 2014), certainly, but also the distribution upstream. The allocation of land to women responds to this imperative, and therefore appropriate policies should articulate this need. The main question is not whether governments should lead or respond to calls from creative women and NGOs but how to put in place an action plan and effective mechanisms for articulating customized policies in villages to increase self and the autonomy of women in meeting basic needs (food, income, health). This contribution is essential for the significant reduction of violence against women in the rural context of Benin while preserving cultural identity.

\section{References}

Aguilar, A., Carranza, E., Goldstein, M., Kilic, T., \& Oseni, G. (2015). Decomposition of gender differentials in agricultural productivity in Ethiopia. Agricultural Economics, 46(3), 311-334. https://doi.org/10.1111/agec.12167

Aizer, A. (2010). The gender wage gap and domestic violence. The American economic review, 100(4), 1847. https://doi.org/10.1257/aer.100.4.1847

Ali, D. A., Deininger, K., \& Goldstein, M. (2014). Environmental and gender impacts of land tenure regularization in Africa: Pilot evidence from Rwanda. Journal of Development Economics, 110, 262-275. https://doi.org/10.1016/j.jdeveco.2013.12.009

Ansoms, A., \& Holvoet, N. (2008). Women and Land Arrangements in Rwanda. Women's Land Rights and Privatization in Eastern Africa, 138-157.

Beaudet, P., \& Haslam, P. (Eds.). (2014). Enjeux et défis du développement international. University of Ottawa Press.

Berge, E., Kambewa, D., Munthali, A., \& Wiig, H. (2014). Lineage and land reforms in Malawi: Do matrilineal and patrilineal landholding systems represent a problem for land reforms in Malawi? Land Use Policy, 41, 61-69. https://doi.org/10.1016/j.landusepol.2014.05.003

Blackden, C. M. et al. (1999). Gender, Growth, and Poverty Reduction: Special Program of Assistance for Africa, 1998 Status Report on Poverty in Sub-Saharan Africa.

Buvinić, M., \& Gupta, G. R. (1997). Female-headed households and female-maintained families: are they worth targeting to reduce poverty in developing countries? Economic development and cultural change, 45, 259 280. https://doi.org/10.1086/452273

Cagatay, N. (1998a). Gender and poverty. UNDP, Social Development and Poverty Elimination Division.

Cagatay, N. (1998b). Gender and Poverty. New York: United Nations Development Programme, Social Development and Poverty Elimination Division, Working Paper 5.

Černi, С̆., \& IsteniČ, M. (2015). Do rural development programmes promote gender equality on farms? The case of Slovenia. Gender, Place \& Culture, 22, 670-684. https://doi.org/10.1080/0966369X.2013.879102

Chernina, E., Dower, P. C., \& Markevich, A. (2014). Property rights, land liquidity, and internal migration. Journal of Development Economics, 110, 191-215. https://doi.org/10.1016/j.jdeveco.2013.03.010

Ellsberg, M. C. et al. (2005). Researching violence against women: practical guidelines for researchers and 
activists.

Garcia-Moreno, C. et al. (2006). Prevalence of intimate partner violence: findings from the WHO multi-country study on women's health and domestic violence. The lancet, 368, 1260-1269. https://doi.org/10.1016/S0140-6736(06)69523-8

Goldstein, S. E. (2011). Relational aggression in young adults' friendships and romantic relationships. Personal Relationships, 18, 645-656. https://doi.org/10.1111/j.1475-6811.2010.01329.x

Holmes, R., \& Jones, N. (2010). Gender inequality, risk and vulnerability in the rural economy. Refocusing the public works agenda to take account of economic and social risks. Background of Report for SOFA.

Huyer, S., \& Mitter, S. (2003). ICTs, globalisation and poverty reduction: Gender dimensions of the knowledge society. Kampala (Uganda). Retrieved from http://gab.wigsat.org/policy.htm

Kabeer, N. (2005). Gender equality and women's empowerment: A critical analysis of the third millennium development goal 1. Gender \& Development, 13, 13-24. https://doi.org/10.1080/13552070512331332273

Kehler, J. (2001). Women and poverty: the South African experience. Journal of international women's studies, 3 , 41-53.

Keswell, M., \& Carter, M. R. (2014). Poverty and land redistribution. Journal of Development Economics, 110, 250-261. https://doi.org/10.1016/j.jdeveco.2013.10.003

Kevane, M., \& Wydick, B. (2001). Microenterprise lending to female entrepreneurs: Sacrificing economic growth for poverty alleviation? World development, 29, 1225-1236. https://doi.org/10.1016/S0305-750X(01)00032-8

Khandker, S. R. (2005). Microfinance and poverty: Evidence using panel data from Bangladesh. The World Bank Economic Review, 19, 263-286. https://doi.org/10.1093/wber/lhi008

Kieran, C., Sproule, K., Doss, C., Quisumbing, A., \& Kim, S. M. (2015). Examining gender inequalities in land rights indicators in Asia. Agricultural Economics, 46, 119-138. https://doi.org/10.1111/agec.12202

Kim, J. C., Watts, C. H., Hargreaves, J. R., Ndhlovu, L. X., Phetla, G., Morison, L. A., ... Pronyk, P. (2007). Understanding the impact of a microfinance-based intervention on women's empowerment and the reduction of intimate partner violence in South Africa. American journal of public health, 97(10), 1794-1802. https://doi.org/10.2105/AJPH.2006.095521

Kimani, E. N., \& Kombo, D. K. (2010). Gender and poverty reduction: A Kenyan context. Educational research and Reviews, 5(1), 24.

Krug, E. G., Mercy, J. A., Dahlberg, L. L., \& Zwi, A. B. (2002). The world report on violence and health. The lancet, 360, 1083-1088. https://doi.org/10.1016/S0140-6736(02)11133-0

Kumar, N., \& Quisumbing, A. R. (2015). Policy reform toward gender equality in Ethiopia: Little by little the egg begins to walk. World Development, 67, 406-423. https://doi.org/10.1016/j.worlddev.2014.10.029

Kumase, W. A. N., Bisseleua, H., \& Klasen, S. (2010). Opportunities and constraints in agriculture: A gendered analysis of cocoa production in Southern Cameroon (No. 27). Courant Research Centre: Poverty, Equity and Growth-Discussion Papers.

Lawry, S., Samii, C., Hall, R., Leopold, A., Hornby, D., \& Mtero, F. (2017). The impact of land property rights interventions on investment and agricultural productivity in developing countries: a systematic review. Journal of Development Effectiveness, 9, 61-81. https://doi.org/10.1080/19439342.2016.1160947

Maksimov, V., Wang, S. L., \& Luo, Y. (2017). Reducing poverty in the least developed countries: The role of small and medium enterprises. Journal of World Business, 52(2), 244-257.

Manfre, C., Rubin, D., Allen, A., Summerfield, G., Colverson, K., \& Akeredolu, M. (2013). Reducing the gender gap in agricultural extension and advisory services: How to find the best fit for men and women farmers. USAID Feed the Future.

Markussen, T., \& Tarp, F. (2014). Political connections and land-related investment in rural Vietnam. Journal of Development Economics, 110, 291-302. https://doi.org/10.1016/j.jdeveco.2014.01.011

Markussen, T., Tarp, F., \& Van den Broeck, K. (2011). The forgotten property rights: Evidence on land use rights in Vietnam. World Development, 39, 839-850. https://doi.org/10.1016/j.worlddev.2010.09.016

Meinzen-Dick, R., Johnson, N., Quisumbing, A., Njuki, J., Behrman, J., Rubin, D., Peterman, A., \& Waithanji, E. 
M. (2011). Gender, assets, and agricultural development programs: A conceptual framework.

Menon, N., Rodgers, Y., \& Kennedy, A. R. (2017). Land Reform and Welfare in Vietnam: Why Gender of the Land-Rights Holder Matters. Journal of International Development, 29, 454-472. https://doi.org/10.1002/jid.3203

Murthy, R. K., Sagayam, J., Rengalakshmi, \& Nair, S. (2008). Gender, efficiency, poverty reduction, and empowerment: reflections from an agriculture and credit programme in Tamil Nadu, India. Gender \& Development, 16, 101-116. https://doi.org/10.1080/13552070701876318

Oseni, G., Corral, P., Goldstein, M., \& Winters, P. (2015). Explaining gender differentials in agricultural production in Nigeria. Agricultural Economics, 46, 285-310. https://doi.org/10.1111/agec.12166

Peterman, A., Behrman, J. A., \& Quisumbing, A. R. (2014). A review of empirical evidence on gender differences in nonland agricultural inputs, technology, and services in developing countries. In Gender in Agriculture (pp. 145-186). Springer Netherlands. https://doi.org/10.1007/978-94-017-8616-4_7

Ragasa, C., Berhane, G., Tadesse, F., \& Taffesse, A. S. (2013). Gender differences in access to extension services and agricultural productivity. The Journal of Agricultural Education and Extension, 19(5), 437-468. https://doi.org/10.1080/1389224X.2013.817343

Ransom, E., \& Bain, C. (2011). Gendering agricultural aid: An analysis of whether international development assistance targets women and gender. Gender \& Society, 25(1), $48-74$. https://doi.org/10.1177/0891243210392571

Seebens, H. (2010). Intra-household bargaining, gender roles in agriculture and how to promote welfare enhancing changes. Background paper prepared for The State of Food and Agriculture, 11.

Sen, G. et al. (1999). Gender mainstreaming in finance. (v. 1): A reference manual for governments and other stakeholders. -(v. 2): A quick guide to gender mainstreaming in finance. https://doi.org/10.14217/9781848596887-en

Sraboni, E., Malapit, H. J., Quisumbing, A. R., \& Ahmed, A. U. (2014). Women's empowerment in agriculture: What role for food security in Bangladesh? World Development, 61, 11-52. https://doi.org/10.1016/j.worlddev.2014.03.025

Suda, C. (2002). Gender disparities in the Kenyan labour market: Implications for poverty reduction. Nordic journal of African studies, 11, 301-321.

United Nations, Economic and Social Council. (2006). Commission on the Status of Women Fiftieth session. Statement submitted by VIVAT International, a non-governmental organization in consultative status with the Economic and Social Council.

Van den Bold, M., Dillon, A., Olney, D., Ouedraogo, M., Pedehombga, A., \& Quisumbing, A. (2015). Can integrated agriculture-nutrition programmes change gender norms on land and asset ownership? Evidence from Burkina Faso. The Journal of Development Studies, 51, $1155-1174$. https://doi.org/10.1080/00220388.2015.1036036

Vandecar-Burdin, T. J. (2011). Victimization. In Ritzer, G., \& Ryan, J. M. (Eds), The Concise Encyclopedia of Sociology. Blackwell Publishing Ltd.

Villamor, G. B., van Noordwijk, M., Djanibekov, U., Chiong-Javier, M. E., \& Catacutan, D. (2014). Gender differences in land-use decisions: shaping multifunctional landscapes? Current Opinion in Environmental Sustainability, 6, 128-133. https://doi.org/10.1016/j.cosust.2013.11.015

Watts, C., \& Zimmerman, C. (2002). Violence against women: global scope and magnitude. The lancet, 359, 1232-1237. https://doi.org/10.1016/S0140-6736(02)08221-1

World Bank. (2001). Engendering Development. New York: Oxford Unversity Press.

World Health Organization. (2012). Understanding and addressing violence against women: Intimate partner violence.

World Health Organization. (2012). Understanding and addressing violence against women: Intimate partner violence.

Zuckerman, E., \& Garrett, A. (2003). Do Poverty Reduction Strategy Papers (PRSPs) Address Gender? A Gender Audit of 2002 PRSPs. Gender Action Washington, DC. 


\section{Copyrights}

Copyright for this article is retained by the author(s), with first publication rights granted to the journal.

This is an open-access article distributed under the terms and conditions of the Creative Commons Attribution license (http://creativecommons.org/licenses/by/4.0/). 